\title{
Applying the Early Adopters Model to Organizations Undergoing Technological Innovation Process
}

\author{
Niv Ahituv ${ }^{1}$, Alon Hasgall ${ }^{2, *}$ \\ ${ }^{1}$ Business Administration Faculty, Tel Aviv University, Tel Aviv, Israel \\ ${ }^{2}$ Learning Technology Faculty, The Technology Institute, Holon, Israel \\ Email address: \\ ahituv@tauex.tau.ac.il(N. Ahituv), Vanola1@gmail.com (A. Hasgall) \\ ${ }^{*}$ Corresponding author
}

\section{To cite this article:}

Niv Ahituv, Alon Hasgall. Applying the Early Adopters Model to Organizations Undergoing Technological Innovation Process. Psychology and Behavioral Sciences. Vol. 8, No. 6, 2019, pp. 158-165. doi: 10.11648/j.pbs.20190806.13

Received: October 24, 2019; Accepted: November 19, 2019; Published: December 2, 2019

\begin{abstract}
This article examines the relevance of the Early Adapter to the process of technological innovation assimilation in a contemporary organization environment._In the 21st century, an organization that wishes to survive in face of the flood of changes in customer requirements, technological innovation, and changing environment must assimilate technological innovation as an ongoing routine by way of carrying out an intensive process of digital transformation. Studies have shown that the digital transformation process affects the employees. It may require additional work effort as well as re-learning, and even change in status. Consequently, resistance may rise. This might affect the success and the effectiveness of the digital transformation in the organization. Therefore, it requires the support of management and the cooperation of the employees, while planning a realistic, concise, and coordinated timetable for the process. The Diffusion of Innovations model (DOI) argues that workers with a positive propensity to technology are more likely to become the early adopters of the digital transformation. According to the Complex Adaptive Systems model (CAS) in organizations, employees who act as fractals (namely, work in a functional autonomy) are prone to encourage technological innovation and utilize resources effectively and share knowledge and solutions tailored to customer needs. _This study examined the relationship between workers function as fractals in an organization with CAS characteristics, and the following traits: development of positive attitudes towards technology, ready to use, and involvement in the assimilation process. According to the DOI model, these are the characteristics of early adopters. Such employees are the most significant contributors to the effectiveness of digital transformation. An empirical study was conducted among 270 subjects who worked in four different organizations in different capacities. The results of the study show that there is a significant relationship between working as an early adopter and working as a fractal in a CAS organization. It also shows that the dimensions "ready to use" and "employee involvement in the process" were the most significant, and exhibited strong and meaningful relationship. The conclusions of the study indicate that the transformation of the organization into CAS, as well as the development of workers as fractals, will encourage the employees to become early adaptors, hence contribute to an efficient and effective process of digital transformation, and to effectively handling disruptive innovation.
\end{abstract}

Keywords: Knowledge Workers, Complex Adaptive Systems (CAS), Early Adopters. CAS Organization, Disruptive Innovation, Digital Transformation, Change Assimilation

\section{Introduction}

The development of technology in the 21 st century is characterized by the rise of smart technology that enables high automation and human/machine integration. This smart technology is expected to generate disruptive effects on each individual organization as well as on the global economy. It has an impact on every aspect of the organization's activity, and, in general, on human life. The breadth and depth of these changes portend a change in the functioning of production [8], management, and government systems, and a change in organizational functioning and human occupations [20] These changes will affect the organization's competitive 
balance due to the possibility of increasing the level of quality, shortening product arrival time, adapting personal products to the customer, improving industry performance, reducing costs, and improving the working conditions of employees [14].

Consequently, the ecosystem that characterizes organizations of all sectors in the present era is very turbulent and highly competitive, especially the process of adapting elements of emerging technologies and disruptive innovation [7]. The organization's management must deal with the implementation of those same emerging technologies and maintain a proper level of profitability and establish effective working relationship with employees.

Are organizations capable of meeting what is required?

A fundamental model that defines the level of acceptance of new technology had been developed a few decades ago the Diffusion of Innovations (DOI) model [18]. According to the model, only $20 \%$ of employees will be able to cope quickly and early with the incorporation of new technologies into the organization and promote work processes quickly and efficiently. These employees are termed early adapters. The implications of that model might be quite problematics for organizations challenged with the process of digitization and introducing disruptive technologies nowadays.

Is this model still relevant today? Can this ratio be changed?

Is it possible to affect and change the ability and will of employees to deal faster, more efficiently and earlier with digital transformation and technologies adaptation?

The purpose of this paper is to examine Rogers' model in accordance with the principle of "adaptive complex systems" in organizations. The paper, based on empirical study, attempts to shed light on the conversion of the organizations to a CAS (Complex Adaptive Systems) mode. This implies changes in structure, processes, and management attitude. It requires the existence of employees who can function as early adopters of technology.

The introductory sections define and explain the major terms and models that lay the base for the discussion. The second part of the paper delineates an empirical study (a survey) that inquires the correlation among the variables pertaining to this research, and exhibits the results. The last part discusses the findings and draws some conclusions.

\subsection{The Diffusion of Innovations (DOI) Model}

The DOI model [17] argues that employees react in advance in different ways to the adoption of technological innovations. According to the DOI model, there are five levels of readiness to adopt new technologies. They can be identified according to their personal, organizational, and external behavior:

The first level is characterized by creative workers and by entrepreneurs; these are called innovators. These employees tend to initiate their own technological innovation, eliminate organizational standardization, and push forward their innovation into the organization.

The second level refers to those who are most willing to adopt technological innovation that introduced by others. These are called early adopters. The early adopters are highly prepared and have a positive attitude towards technological innovation. An early adopter can be identified as an employee who makes it easy to access organizational information, has social and professional connections, shares knowledge, is willing to give up formalization at work, and creatively deals with procedures and standards in order to be ahead in adopting any new technology. Such an employee will base his/her work and solutions on the adoption of innovative technology that enters the organization. $\mathrm{He} / \mathrm{she}$ is an employee that the organization wishes to rely on in every process of digital transformation and assimilation. These employees do not need to be pushed and supported by technology adoption. They will expose new technologies and aspire to adopt them in the organization without much training and support.

The subsequent levels of adoption of technologies are the usual "mass" of workers, who, as noted, need guidance, emotional support, and a great deal of time.

The next level in adopting technology will be "late" adopters. These employees are not interested in investing time and effort in technologies, making implementation difficult, and adopting technologies only if they are compelled to do so. They usually expect to be rewarded accordingly.

Finally, last level of employees is those who are not interested in any changes and will make it very difficult to assimilate technological innovation. These are called laggards. These workers are unwilling to accept any change [and certainly technological change].

It seems that, inherently, there are early adopters among the organization's employees. They have great potential to help the organization to adopt technological innovation and carry out the fast and effective process of digital transformation. According to the DOI model, it is expected that approximately $15 \%$ of employees are early adopters [19] These employees are well aware of the perceived features of innovation and have a positive attitude towards it [24].

\subsection{Smart Technology and the Organization}

In recent years, traditional industries, such as High Tech and New Media Enterprises, have begun to face the challenge of rapid outbreak of technologies that disrupt the value chain business [7]. As a result, organizations have adopted smart technologies in the fields of IT, global communications systems, social networks, mobile applications, and artificial intelligence. Today, smart technology is considered an essential part of the organizational resources that enables the upgrading and accelerating of manufacturing processes, marketing, and services beginning in the planning stage, and up to the delivery to the customer. However, these changes create a transformation of processes, and require the managers of the organizations to carry out massive assimilation processes with far-reaching adjustments of internal structure and processes [2]. Executive surveys show that smart technology can improve business processes, 
leverage products and services, and improve customer experience through innovative solutions. The annual organizational expenses for the technological transformation processes, including hardware, software, social technologies and consulting services, will exceed $\$ 1.3$ trillion, and will be doubled by 2021 The traditional sectors that will meet the fastest growth in the next five years are construction, retail and health services [22].

A study by Dell EMC found that $90 \%$ of 4,000 US managers believe that digital transformation is necessary in every organization. $81 \%$ of the executives see digital transformation in the organization as a condition for the organizations to sustain relevance in the market. $88 \%$ agreed with the claim that they have pressure from customers to provide "smart" services - automated and customized, and therefore they must implement smart technologies for collecting information such as IOT and Digital, as well as data analysis and artificial intelligence. $96 \%$ of the managers say the process of digital transformation in IT systems has already begun. This will contribute dramatically to improving the organization's decision-making processes, to the ability to meet profit targets, and to improve market competitiveness [9].

Digital transformation in an organization occurs when technological innovation develops within the organization or imported into the organization from external sources. The development of innovation requires the sharing of ideas and knowledge, and the support of creative and applied solutions in a planned, ongoing, and professional manner [13]. Every time there is a change in customer consumption habits, a new technology has reached the commercial level, or a new competitor breaks through the entry barriers, there will be an immediate increase in the search for technological innovation. Therefore, many organizations have begun to proactively approach technology development sites, and constantly review technological changes and innovations in their environment, as well as innovative methods in an attempt to identify innovation that will enable the rapid development of services that might improve competitiveness [16]. Therefore, an organization that wishes to stay on a continuous road of innovation must sense the changes in the market, define future organizational needs, and try to locate innovative technologies that can upgrade its competitive ability or threaten to disrupt its current business model [7]. The process of innovation and organizational transformation has become common and central to the life of the organization. Technological innovation is a key component in developing organizational capabilities and a key factor in building the business model.

\subsection{Organizational Factors in the Process of Digital Transformation}

Despite the organizational need, not all employees have the same ability to cope with technological innovation [8]. Various models describe the organizational factors required for the successful and high-quality transformation to digital, and to assimilation of technological innovation in the organization. The Digital Maturity Index reflects the ability of the organization's management and employees to cope with external changes and to adjust jointly and consensually the internal work processes for the innovative change. This index, developed by Deloitte, makes it possible to characterize those organizations that are likely to succeed in a process of digital transformation [1] The Digital Matriculation Index (DMI) claims that supporting employees with a positive attitude and readiness to change and assimilate technology in the organization is one of the important factors in the success of the transformation process. Supporting the employees with positive attitude to technology will affect the rapid and qualitative process of adapting solutions and work processes, even if some deviation from management and familiar methods is required. Another model called TOE, Technology, organization, and environment contains an integrative reference to the organizational factors that influence the development of technological innovation in the organization: the technological factor - the knowledge of technology, the understanding of the benefits of technology, and positive attitudes towards technology. The organizational factor agreement and involvement of management, employee involvement, and clarity of work processes. The environmental factor - sensitivity to changes and innovation in the organization's environment and among competitors; understanding customer needs and adapting them (see Graph 2). According to the TOE model, each of these factors requires specific attention, while interacting between customer requirements, employee attitudes, organizational requirements, and even compliance with government regulations- According to these models, the organization has the duty to integrate all of the organization's entities in order to create a successful digital transformation and assimilate technological innovation in the organization.

\subsection{Working Under Digital Organizational Transformation Process}

Digital transformation can upgrade an employee's abilities, help diversify his/her work, and even promote his/her position. However, it might also go worse, since the employee must accommodate to rapid changes in organizational processes. Those may involve rapid changes in working processes, adding or downgrading roles, and replacement or restructuring of familiar working methods. This may adversely affect the employee's status, lead to additional tasks and working hours. The concept of the "rational reaction" claims that each employee analyzes the changes in accordance with what is required from him/her, and the reward he/she deserves. The employee evaluates the revised position with regards to the perceived personal benefits. Disagreement and problems in coordinating the process between management and employees may pose threats to the employees, making it difficult for the workers' regular activities, their status, and even the amount of their income. It has been found that organizational changes based on technological innovation may create an immediate burden 
on workers, due to excess tasks and more work, and, hence, a perception of uselessness and resistance to the assimilation [3]. The "rational perception" model teaches us that if a digital transformation in an organization is perceived as detrimental to the employees, their motivation to succeed and to implement the new organizational goals will be reduced [21]. They may delay the process of change, impair the assimilation of innovation, and even eliminate it [2].

Therefore, transformation processes and the assimilation of innovation in the organization require mutual commitment of management and employees. The organization must create positive attitudes towards the assimilation of the new technology into the organization, by involving the employees in the process, strengthening their status, and rewarding them [6]. This model suggests that an organization that is interested in an effective and rapid digital transformation process must influence the employees' positive approach to the technology and implementation process of the innovation. These workers will then be able to adapt to technology and connect it to organizational solutions. However, this effect requires a long and expensive process. An organization that wants to improve the positive attitude of its employees should plan a process of training and support by connecting employees to technology, locating employees who agree to learn, and supporting them in practical use of the new technology. Executives should be trained to create positive messages about technology and teach them to support employees willing to learn and assimilate the new technology.

\subsection{Employees in Organizations of the Cas Type}

It can be said that the environment around us changes continuously. The organisms in nature are constantly required to adapt to these changes. High-survivability organisms are the ones that quickly and efficiently adapt to the changes in nature around them. Studies have shown that highly survivable organisms are constructed as complex adaptive systems (CAS). Thus, the human body contains many organs that are built as CAS. One of them is the largest organ - the skin. Like a tree, the skin contains many cells that are essentially similar to each other, functions similarly, but each cell can react automatically and immediately to changes occurring in its environment, while echoing to other cells.

Parallel to organisms in nature, human society was also required to adapt to changes in the environment. Studies have shown that in a form of CAS, the level of adaptation to external changes increases [12]. Another study emphasizes that human can optimally adapt to environmental changes by using CAS organizations [3]. Further studies have shown that the more organizations have CAS characteristics, the greater their perception of success in dealing with changes, competition and disruptive innovation. It was also found that there is a relationship between the organization characteristics of CAS and the development of employees as fractals - subsystems that are ready and able to make autonomous decisions and share solutions according to the needs of the organization. These employees act as "knowledge workers" who combine their needs with the organization's goals, know how to create new knowledge relevant to their task, and share with their employees while updating their knowledge. This employee knows how to effectively utilize the physical and social resources available to him, to experience and identify changes in the organization's external and internal environment, and to enable the organization to cope with these changes by providing an immediate, localized response [23] These workers have been shown to have a positive attitude towards technological innovation and are willing to use new digital technology in the organization [10]

\section{Methodology}

\subsection{Research Question}

Various studies have found a connection between the Complex Adaptive System (CAS) and the Diffusion of Innovation (DOI) models. In both models, one can find a reference to face changes in the environment and to articulate a process of adaptation. In the case of the DOI model, this is usually in response to technological adaptation. Those characterized as early adopters lean towards a more rapid use of new [17]. In the case of the CAS model, we can identify knowledge workers that are acting as autonomous fractals addressing complex environment.

Is it possible to assume that there is a correlation between characteristics of knowledge workers in the CAS organization and characteristics of early adaptors?

The advantages are clear. Employees who are characterized as early adopters will be a highly desirable for an organization that is in a process of digital transformation, since they adopt new technological innovation quickly and efficiently with less objections. We assume that such group of employees will support effectively the organization's technological transformation processes, help to better assimilate the organization's innovative technology, and promote organizational innovation [24].

If our hypothesis is correct and there is a correlation between knowledge workers and the early adopters' characteristics, these workers which have position of perceived features of innovation, can be identified by the characteristics of knowledge workers.

\subsection{Research Variables}

\subsubsection{Independent Variables}

The early adapters characteristics: describe positive workers position of implementing and using technological innovation; can be identified by three dimensions [15]:

A. Involvement in organizational processes

B. Attitude towards technological innovation

C. Ready-to-use, innovative technologies

\subsubsection{Dependent Variable}

Workers as a fractal in the CAS organization.

An employee with the ability to function as a fractal has 
four dimensions that arise from the internal work environment of the CAS organization [23]:

Functional autonomy - Creation and operation of local and immediate solutions, in accordance with the organization's goals.

Integration and sharing - sharing knowledge and resources, echoing and updating their solutions and knowledge to the rest of the employees in a continuous and permanent process.

Environmental sensitivity - familiarity and understanding with organizational challenges, key business models, and immediate changes in the environment.

Socially connected - professional and social networking with other employees [10].

\subsection{Sample}

The sample included 270 employees with an average of 5 years of seniority, and 15.2 years of school [2.6 SD].

The respondents were employed in 4 different types of occupations: $22.7 \%$ of the workers were in technology and computers; $18.4 \%$ in education and teaching; sales and marketing $-8.6 \%$; others $-28.6 \%$.
Respondents were employed in 4 types of organizations; a total of 8 organizations participated in the sample: 2 from education organizations; 2 from heavy industry; 2 from high tech; and 2 from services.

Data collection and analysis was performed by a professional company specializing in distribution and analysis of questionnaires (named "Ipanel"), (http://www.ipanel.co.il/en/academic-research/).

\subsection{Research Tool}

The respondents were asked to respond to 30 questions through an online textual questionnaire. The questions were designed to examine various dimensions of the work of the respondents within the organization.

\section{Findings}

The questionnaire included questions relating to each dimension of each variable. The answers were on a scale of 1-5. $1=$ Very low to $5=$ Very high.

Table 1. Descriptive statistics of the research variables.

\begin{tabular}{lll}
\hline Average & Description & Variable code \\
\hline 3.7 & Involvement in organizational processes & Q1 \\
2.3 & Attitude towards technological innovation & Q2 \\
2.6 & Ready-to-use, organizational innovative technologies & Q3 \\
1.9 & Degree of functional autonomy & CAS 1 \\
2.2 & Degree of environmental sensitivity & CAS 2 \\
2.1 & Degree of knowledge sharing & CAS 3 \\
2 & Degree of professional networking & CAS 4 \\
\hline
\end{tabular}

Table 1 shows that the average level of the Involvement dimension from the early adopter dependent variable was the highest [3.7]. The average of the ready-to-use dimension was lower yet relevant [2.6]. The dimensions "Attitude towards technological innovation" was the lowest [2.3].

The average of all the dimensions from the independent variable was nearly the same [1.9 - 2.2].

Table 2. Researches variables correlations \& significance.

\begin{tabular}{lllll}
\hline \multirow{2}{*}{ R Square } & \multicolumn{2}{l}{ Employee reference to technological innovation } & Characteristics of the knowledge worker as a fractal \\
\cline { 2 - 4 } & involvement & Attitude & Ready to use & CAS 1: Degree of functional autonomy \\
\hline 0.02 & $\mathrm{~F}=2.8, \mathrm{p}=0.042$ & $\mathrm{~F}=2.4, \mathrm{p}=0.122$. & $\mathrm{F}=3.2, \mathrm{p}<0.001$. & CAS 2: Degree of environmental sensitivity \\
0.031 & $\mathrm{~F}=3.7, \mathrm{p}=0.012$ & $\mathrm{~F}=1.3, \mathrm{p}=0.254$ & $\mathrm{~F}=3.1, \mathrm{p}<0.001$ & CAS 3: Degree of knowledge sharing \\
0.057 & $\mathrm{~F}=3.9, \mathrm{p}<0.001$ & $\mathrm{~F}=1.0, \mathrm{p}=0.404$ & $\mathrm{~F}=3.6, \mathrm{p} 0.001>$ & CAS 4: Degree of professional networking \\
0.057 & $\mathrm{~F}=3.7, \mathrm{p}=0.001$ & $\mathrm{~F}=1.4, \mathrm{p}=0.203$ & $\mathrm{~F}=3.5, \mathrm{p}=0.002$ & \\
\hline
\end{tabular}

An analysis of the correlations and significance Table 2 reveals:

1. The relationships between the dimensions of the depended variable "working knowledge as a fractal" and the dimension: involvement were all positive and significant: $(\mathrm{F}=2.8, \mathrm{p}=0.042, \mathrm{~F}=3.7, \mathrm{p}=0.01, \mathrm{~F}=6.9$, $\mathrm{p}<0.001, \mathrm{~F}=3.7, \mathrm{p}=0.001$ )

2. The relationships between the dimensions of the depended variable "working knowledge as a fractal" and the dimension: Ready to use were all positive and significant: $(\mathrm{F}=3.2, \mathrm{p}<0.001 ., \mathrm{F}=3.1, \mathrm{p}<0.001, \mathrm{~F}=3.6$, $\mathrm{p}<0.001, \mathrm{~F}=3.5, \mathrm{p}=0.002)$.

3. The relationships between all four dimensions of the depended variable "working knowledge as a fractal" and the dimension: Attitude were not significant.

When the correlation between the dimensions of the early adopter variable and the dimensions of the "knowledge worker" variable is analyzed in an organization with CAS characteristics, it is clear that employees having operational autonomy are up to date with organizational challenges and use social and operational integration tools.

When the executives involve them in deciding on necessary changes and implementing new technology, these employees tend to become early adopters. These knowledge workers understand the benefits that technological innovation might provide them during the transformation and are, therefore, likely to make immediate practical assimilation of the technological innovation. It is interesting to learn that this 
readiness of the employees does not only change their position, but the actual performance improves as they become early adapters. It was also found that the other dimensions are not relevant to the employees attitude towards technological innovation.

The strength of these connections was examined between different types of organizations and between the various professions of the workers. A significant, positive and strong relationship was greater than 4. A moderate relationship is considered a relationship between 3 and 4 and a weak link is a relationship less than 3 . The strength of the ties indicates not only significance, but also the involvement and employability of workers in the different professions and perhaps also the influence of the organizational culture on the development of Working as early adopters.

Table 3. Chi-squared test.

\begin{tabular}{lllll}
\hline Industry & Education & High Tech & Services & \\
\hline Medium Positive & Medium Positive & Strong Positive & Medium Positive & IT \\
- & Medium Positive & - & - & Teachers \\
\hline
\end{tabular}

Table 3 shows that the relationships between the variables were stronger among IT workers that was engaged in technological, especially in the high-tech sector. A moderate but steady relationship was found among teachers, especially those in the education sector.

\section{Discussion}

A process of digital transformation usually takes place when there is a decision to assimilate digital technological innovation in the organization. This process is necessary because of changes in customer requirements and the development of new technologies that may disrupt the business model of the organization. Such situation is likely to occur in many organizations over the next few years [7]. Digital transformation is undertaken after a decision is made regarding selection of innovation technologies and/or revisions in work processes. An organization that decides to perform a digital transformation is committed to carry out changes in work processes and organizational culture. The implementation of an assimilation process is considered an essential factor in the digital transformation. The traditional concept of the assimilation process relies on a top down approach. Without a clear decision and management support, the process will not succeed. Managers need to understand technological innovation, adapt it to the desired business model, modify work processes [16], commit to organizational transformation, support revised work processes, and back employees during the implementation phase [2]. The traditional top-down approach emphasizes the organizational hierarchy and the managers' commitment to take responsibility for planning and execution. The basic assumption of this approach is that the responsibility of the managers is comprehensive. The responsibility relates to determining procedures, characterizing the training, applying a system of rewards, and moral support. They must provide an effective outcome of the transformation, increase the organizational competence to answer the customer's demands, and, at the same time, cover the investment, and even increase the profitability. Research has found that such cases might increase the emotional stress among the managers, so they strengthen supervision and control [4] over their subordinates to the extent of undermining their freedom of action and their perception of benefit [5].
Digital transformation should be a systemic process that affects every employee and every work process in the organization. A process that relates to the change and adaptation of industrial technologies and information systems, to methods of work, procedures, and employees' conditions [7]. In order to assimilate innovation in the organization, employees must be familiar with the technology, the changes in their work processes, and above all, the benefits that they gain and those that the organization gains. The efficiency of the digital transformation process will enable the organization to save resources, hone its business model, and create employees' commitment to the process [2]. It will facilitate facing the challenge of competition and the changing environment, as well as the demands of customers [5]. According to the "rational operation" model, employees examine at any given moment the balance between the level of effort required, and the reward they perceive as well as their status in the organization and their ability to achieve their wishes [3]. Therefore, an organization must create a mutual understanding with its employees and jointly strengthen the ability to cope with changes in the environment [1].

This study reinforces the relationship between knowledge workers and the DOI model, which claims that early adopters recognize the perceived features of tech-innovation [18]. These workers are identified by three dimensions: They have a positive attitude toward technological innovation; they are involved in the process of assimilation; and they are ready to use in technological innovation [15]. These employees will be committed to the process of digital transformation and will be a significant asset to an organization in that process.

\section{Conclusions}

When an organization is undergoing a digital transformation, the importance of employees who can function as early adopters is crucial. These employees more likely to support changes in the organization that are derived from implementation of technological innovation. They will favor the immediate use of technological innovation in their work, create compatibility between technological innovation and the activities of the organization, and promote the innovative technologies and processes in the organization. In addition, these employees will perform experiments to assess 
the efficiency of the fruits of the innovation in the organization (Henderson, 2017). Therefore, the most important conclusion of this study is to provide a suitable and attentive working environment for employees promoting changes or innovation in the organization [especially in the process of digital transformation]. A workspace that allows those employees to have both operational autonomy and knowledge sharing and integration, will facilitate their ability to function as "fractals" in an organization that has "Complex Adaptive System" characteristics. According to this study, they will develop a positive attitude towards innovation and even adopt it more quickly as early adopters. These employees will be able to offer immediate solutions, adopt others' solutions, and implement these solutions autonomously and quickly, sharing resources and knowledge.

Some additional conclusions indicate:

1. The involvement of early adapters in the process is the most dominant dimension.

2. The ready-to-use dimension affects the positive and significant relationship between an early adopter and the variable "working as a fractal in the CAS organization", especially among IT workers and the high-tech sector.

3. Having CAS characteristics contribute directly to the organization's ability to adapt rapidly to changes in the environment by supporting early adopters, who will accelerate the process of digital transformation in the organization.

Following the conclusions of this study, it can be assumed that an organization that adopts characteristics such as CAS will be able to support knowledge workers as fractals and thus provide benefits to employees who are clearly oriented towards early and rapid use of technological innovation. These employees will be able to work autonomously, maintain regular contact with other employees, share knowledge and resources, and respond quickly to changes in the environment, especially when it comes to technological disruption or the need to effectively assimilate innovative technologies into the organization's work processes.

6. A road map to workers as early adopters in CAS organizations

This study clearly presents the correlation between the CAS characteristics of the working environment and the development of knowledge workers as early adaptors. The combination of the two models enables us to understand the methodology for better coping with digital transformation. This methodology is instrumental in developing and supporting employees as early adopters.

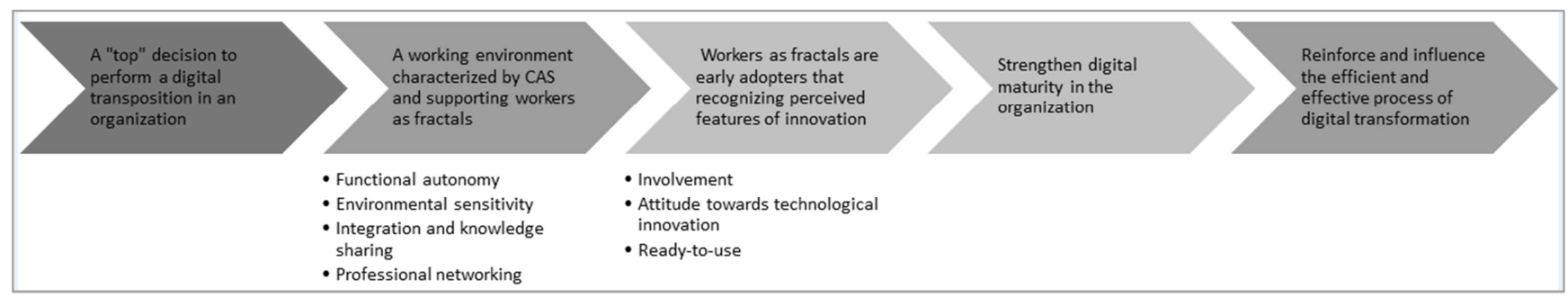

Figure 1. Road Map to knowledge worker as early adopter in CAS organization.

Figure 1 indicates the process of implementation of the methodology as recommended by this study.

1. The process begins with a managerial decision to adapt the organization to changes in the market through digital transformation. This decision must be disseminated top down.

2. Next, it is necessary to create and support a CAS-like working environment. This would imply flattening the organizational structure, encouraging employees to take responsibility for a project/product/service from start to end.

3. In addition, through ICT and social networks, the organization should support transparency, update business models, and share knowledge about environmental changes and innovative solutions tailored to customers' needs. Given the results of the research and previous studies, this stage will encourage employees to develop an orientation for technological innovation and to take part in the process of implementing innovative technology in the organization.

4. Managers have to support, encourage, and reward workers who possess characteristics of early adopters.
The current study indicates that employees involved in the assimilation process in an organization where the internal work environment characterized by CAS can develop as early adopters. Insofar as these employees will be able to make effective use of technological innovation and will make rapid and effective use of the new technology embedded in the organization.

As far as the ongoing process of digital transformation in the organization is concerned, employees with the ability to make quick and effective use of technology (namely, early adapter) can be a significant asset to the organization.

\section{References}

[1] Anderson, C and Ellerby, W. (2018). Digital Maturity Model Achieving digital maturity to drive growth. Deloitte.

[2] Anjariny, A. H. (2016). Assessing Organizations Readiness toward Business Intelligence Systems: A Proposed Hypothesized Model. International Journal of Information Technology Convergence and Services (IJITCS) Vol. 6. Retrieved http://aircconline.com/ijitcs/V6N1/6116ijitcs02.pdf. 
[3] Beesen, J. Ford, J and Meurer, J. (2011). The Private and Social costs of Patent Trolls. Boston University. 11-45.

[4] Bennet, A. and Bennet, D. (2002). Characterizing the Next Generation Knowledge Organization. Knowledge and Innovation: Journal of The Kmci. Retrieved from: https://www.kmci.org/media/bennetcharacterizingki11.pdf.

[5] Bennett, R. and Gabriel, H. (1999). "Organizational factors and knowledge management within large marketing departments: an empirical study", Journal of Knowledge Management, Vol. 3 Issue: 3, pp. 212-225.

[6] Chen, D. (2010), Schooling as a Knowledge System: Lessons from Cramim Experimental School. Mind, Brain and Education. 4:1. Pp: 8-19.

[7] Christensen, C. M, Bartman, T., and Van bever, D. (2016), "The Hard Truth about Business Model Innovation". MIT Sloan Management Review.

[8] Dan, V., Osterheider, A., \& Raupp, J. (2018). The Diffusion of Innovations in Agricultural Circles: An Explorative Study on Alternative Antimicrobial Agents. Science Communication, 41 (1), 3-37. Retrieved from: https://doi.org/10.1177/1075547018819159.

[9] DeMattia, A. McKnight, J. Gahm, J and Keane, M. (2018). Research Proves IT Transformation's Persistent Link to Agility, Innovation, and Business Value. Dell EMC and Intel and is distributed under license from ESG. Retrieved from: https://www.dellemc.com/en-us/it-

transformation/index.htm\#cobrand=intel\&overlay=/collateral/ analyst-reports/esg-it-transformation-report-agilityinnovation-business.pdf.

[10] Hasgal, A and Ahituv, N. (2017). "The Development of Knowledge Workers in an Organization characterized as Complex Adaptive Systems (CAS)", 14th International Conference on Intellectual Capital, Knowledge Management \& Organisational Learning”, Hong Kong.

[11] Hasgall, E. A. (2015), From assimilation to acclimatization of social digital Technology in organizations. International Journal of Computer Systems (IJCS). Vol 2 Issue 10. Retrieved http://www.ijcsonline.com/IJCS/IJCS_2015_0210001.pdf.

[12] Holland, J. H. (2006), "Studying complex adaptive systems", Journal of Systems Science and Complexity, Vol. 19 No. 1, pp. 1-8.
[13] Hartono, H and Basuki, Yt. (2015) The impact of knowledge management and Knowledge entrepreneur on innovation and firm performance. People innovation Excellence: Retrieved from: http://sbm.binus.ac.id/2015/10/21/the-impact-ofknowledge-management-and-knowledgeentrepreneur-oninnovation-and-firm-performance/.

[14] Jackson, Mo. (2008). Social and economic networks. Princeton University Press, Princeton.

[15] Oreg, S. (2003), "Resistance to change: Developing an individual difference measure", Journal of Applied Psychology, Vol. 88 No. 4, pp. 680-693.

[16] Potter, K and McGittigan, G. (2013) IT Metrics: A Critical Evaluation of Decentralized IT Spending and Digital Enterprise Readiness. Gartner, Inc.

[17] Rogers, Everett. M. (1962). Diffusion of Innovations. New York: The Free Press of Glencoe. P. 13. 5.

[18] Rogers, E. M., Medina, U. E., Rivera, M. A. and Wiley, C. J. (2005). Complex Adaptive Systems and the Diffusion of Innovations. The Innovation Journal: The Public Sector Innovation Journal, Vol. 10 (3), 29.

[19] Robertson T. S. (1967). The Process of Innovation and the Diffusion of Innovation Journal of Marketing, Vol. 31. pp. 1419.

[20] Schwab, K. (2017). The Fourth Industrial Revolution. New York: Crown Publishing Group.

[21] Moghavvemi, S. Salleh, N. A. M. and Standing, C. (2016). "Entrepreneurs adoption of information system innovation: The impact of individual perception and exogenous factors on entrepreneur's behavior", Internet Research, Vol. 26 (5), pp. 1181-1208.

[22] Shirer, M and Eileen, S. (2017). IDC Forecasts Worldwide Spending on Digital Transformation Technologies to Reach \$1.3 Trillion in 2018. IDC Retrieved from: https://www.idc.com/getdoc.jsp?containerId=prUS43381817.

[23] Shoham, S., \& Hasgall, A. (2005). Knowledge workers as fractals in a complex adaptive organization. Knowledge and Process Management, 12 (3), 225-236.

[24] Singhal A. and Svenkerud, P. J. (2019). Flipping the Diffusion of Innovations Paradigm: Embracing the Positive Deviance Approach to Social Change. Asia Pacific Media Educator. Retrieved from: https://doi.org/10.1177/1326365X19857010. 